\title{
Letter
}

\section{Making inferences from the reintroduction literature: a response to Bajomi et al.}

In reintroduction, as in all aspects of conservation biology, projects should not take place in isolation but should build on information from previous research and management. This includes collating published literature and drawing inferences from comparative assessments. Bajomi et al. (2010) make a strong contribution by compiling 3,826 reintroduction-related publications, describing the dispersal of this literature among publication types, and evaluating bias.

Bajomi et al.'s (2010) analysis of bias is taxonomically focused; i.e. they compare numbers of publications featuring different taxa both to the relative numbers of species in these taxa and to the numbers of reintroductions involving the taxa. Unsurprisingly, there is a bias toward vertebrates in the published literature, particularly birds and mammals. Bajomi et al. (2010) conclude that 'the dispersed and biased nature of the literature means that we may be failing to accumulate a reliable evidence base to underpin decision making' and that 'managers should try to publish the outcome of every programme, and editors and peer reviewers should lessen the bias in their journals'. However, we are not aware of any evidence of taxonomic bias in evaluation of reintroduction papers. More importantly, we caution that Bajomi et al.'s (2010) conclusion about failure to acquire an evidence base may reflect assumptions that could hinder progress in reintroduction biology.

The first apparent assumption is that knowledge in reintroduction biology is taxon-specific; i.e. reintroduction outcomes for a particular taxon will improve only with research on that taxon. Although issues in reintroduction may be correlated with taxon, we suggest it is better to categorize species by ecological and life history traits and to focus on key processes (e.g. post-release dispersal or survival) rather than taxa. Progress in any discipline requires easy-to-study model systems, and bias toward bird and mammal systems in reintroduction biology partly arises because these taxa tend to be relatively easily studied and/or give fairly rapid results. We agree that there should be greater research emphasis on reintroductions involving other taxa, and note that invertebrate systems may be best for addressing many questions. However, managers should consider relevant research involving all taxonomic groups.

The second apparent assumption is that the literature consists of descriptive reports on reintroduction projects, which would lead to the expected correspondence between project characteristics (e.g. taxa featured) and publications.
Although much of reintroduction literature to date does consist of such reports, there is increasing focus on strategic question-based research (Seddon et al., 2007; Armstrong \& Seddon, 2008). Strategic research means taking advantage of good systems for addressing questions of general interest to reintroduction biology; hence some reintroductions will inevitably feature in numerous publications, leading to 'biases' that may not be undesirable.

We suggest that authors making inferences from the reintroduction literature should distinguish between three types of publications: (1) descriptive reports of projects, (2) strategic question-based research, and (3) comparative analyses. Although we advocate greater emphasis on (2) and (3) (Seddon et al., 2007), we agree with Bajomi et al. (2010) that managers should publish programme outcomes. However, many journals are unlikely to publish such accounts unless they provide novel approaches of general interest, and this partially accounts for the wide dispersal of reintroduction publications reported by Bajomi et al. (2010). We suggest descriptive accounts be published in journals such as Conservation Evidence, or in online sources; e.g. accounts of New Zealand reintroduction projects are published at http://rsg-oceania.squarespace.com/. As noted by Sutherland et al. (2010), descriptive accounts will have greater value if they include parameter estimates, such as population sizes or growth rates, accompanied by information on management treatments, thus facilitating useful meta-analyses.

Doug P. ARMSTRONG

Ecology 624, Massey University, Private Bag 11222, Palmerston North, New Zealand. E-mail D.P.Armstrong@massey.ac.nz

PHILIP J. SEDDON

Department of Zoology, University of Otago, Dunedin, New Zealand.

\section{References}

Armstrong, D.P. \& Seddon, P.J. (2008) Directions in reintroduction biology. Trends in Ecology \& Evolution, 23, 20-25.

Bajomi, B., Pullin, A.S., Stewart, G.B. \& Takács-Sánta, A. (2010) Bias and dispersal in the animal reintroduction literature. Oryx, 44, 358-365.

Seddon, P.J., Armstrong, D.P. \& Maloney, R.F. (2007) Developing the science of reintroduction biology. Conservation Biology, 21, 303-312.

Sutherland, W.J., Armstrong, D.P., Butchart, S.H.M., EARnhardt, J.M., EwEn, J.G., Jamieson, I.G. et al. (2010) Standards for documenting and monitoring bird reintroduction projects. Conservation Letters, 3, 229-235. 